\title{
Article \\ Health Literacy and Frailty in Community-Dwelling Older Adults: Evidence from a Nationwide Cohort Study in South Korea
}

\author{
Hye-Ri Shin ${ }^{1}$, Eun-Young Choi ${ }^{2}$, Su-Kyung Kim ${ }^{3}$, Hee-Yun Lee ${ }^{4}$ and Young-Sun Kim ${ }^{3, *}$ \\ 1 Department of Gerontology, Graduate School of East-West Medical Science, Kyung Hee University, \\ Yongin 17104, Korea; ltc.shinhyeri@gmail.com \\ 2 Leonard Davis School of Gerontology, University of Southern California, Los Angeles, CA 90089, USA; \\ choieuny@usc.edu \\ 3 AgeTech-Service Convergence Major, Graduate School of East-West Medical Science, Kyung Hee University, \\ Yongin 17104, Korea; godwithme2017@khu.ac.kr \\ 4 School of Social Work, The University of Alabama, Tuscaloosa, AL 35487, USA; hlee94@ua.edu \\ * Correspondence: ysunkim@khu.ac.kr; Tel.: +82-31-201-3719
}

\section{check for}

updates

Citation: Shin, H.-R.; Choi, E.-Y.; Kim, S.-K.; Lee, H.-Y.; Kim, Y.-S Health Literacy and Frailty in Community-Dwelling Older Adults: Evidence from a Nationwide Cohort Study in South Korea. Int. J. Environ. Res. Public Health 2021, 18, 7918. https://doi.org/10.3390/ ijerph18157918

Academic Editors: Igor Grabovac and Lee Smith

Received: 24 June 2021

Accepted: 24 July 2021

Published: 27 July 2021

Publisher's Note: MDPI stays neutral with regard to jurisdictional claims in published maps and institutional affiliations.

Copyright: (c) 2021 by the authors. Licensee MDPI, Basel, Switzerland. This article is an open access article distributed under the terms and conditions of the Creative Commons Attribution (CC BY) license (https:// creativecommons.org/licenses/by/ $4.0 /)$.
Abstract: Health literacy is closely associated with poor health outcomes and mortality. However, only a handful of studies have examined the association between health literacy and frailty status. The current study used data from a nationwide sample of Korean adults aged 70-84 collected from 10 cities, each of which represents a different region of South Korea $(n=1521)$. We used the propensity score matching (PSM) method to minimize the potential selection bias and confounding factors that are present in observational studies. After PSM, demographic and health-related characteristics between the limited health literacy $(n=486)$ and the nonlimited health literacy $(n=486)$ groups were not significantly different. Multinomial logistic regression analyses were conducted for the PSM-matched sample to examine the association between health literacy and frailty outcomes, where the robust group was set as a reference. Limited health literacy significantly increased the risk of pre-frailty $(R R R=1.45, p=0.02)$ and frailty $(R R R=2.03, p=0.01)$ after adjusting for demographic and health-related factors. Our findings underscore the need to foster health literacy programs and provide preliminary evidence to inform tailored intervention programs so that we might attenuate the risk of frailty in the older population.

Keywords: health literacy; frailty; community-dwelling older adults; propensity score matching

\section{Introduction}

Frailty refers to a state of significant physiological decline with aging, and it is characterized by increased vulnerability to stressors and reduced functional reserves [1]. Frailty is associated with adverse health outcomes, including falls, hospitalization, poor quality of life, and mortality [2,3]. The Fried frailty phenotype [4] proposed the following five criteria for the diagnosis of frailty: (1) unintended weight loss, (2) fatigue, (3) grip strength, (4) reduced walking speed, and (5) decreased physical ability. People with three or more symptoms are identified as frail, and those with two symptoms are classified as being in the pre-frailty stage [4]. Previous studies found that frailty status is related to a wide range of sociodemographic characteristics (e.g., education and economic status), physical health conditions, and health behaviors [5,6], as well as psychological risk factors such as cognitive impairment, depression, and emotional frailty [7-11]. Continued research efforts are warranted to identify modifiable preventive and risk factors of frailty, which will contribute to its prevention and management.

A recent growing body of health literature has focused on the role of health literacy. Health literacy is defined as one's cognitive and social skills for reading, understanding, assessing, and using accurate health information to make informed health-related decisions 
and to promote good health [12]. Limited health literacy not only leads to poor recognition and bad management of one's health condition, but also acts as a barrier to communication with health professionals and to access to medical treatment [13-15]. Systematic reviews have shown that health literacy is closely associated with poor health outcomes and mortality [16,17].

However, only a handful of studies have examined the relationship between health literacy and frailty status [18-24]. For example, in a study of 603 community-dwelling older adults in Taiwan [18], low health literacy was associated with higher odds of pre-frailty and frailty. The significance remained even after controlling for demographic and health covariates. Shah et al. surveyed 470 adults with an average age of 57 years, and found that those with high health literacy had a lower risk of frailty [21]. Similarly, according to a study conducted by Yamada et al. older adults with inadequate health literacy were disproportionately higher in the pre-frailty (52.2\%) and frailty (65.7\%) groups than they were in the healthy group (37.6\%) [23].

Prior studies have provided some initial evidence for the significant role of health literacy in determining frailty status; however, they mainly used small, convenience samples recruited from geographically limited areas, thus limiting the representativeness of the findings. In addition, not all confounders, such as health behaviors, were adjusted in previous research models. Thus, it remains unclear whether health literacy leads to an increased risk of frailty among older adults. To address these research gaps, the current study used data collected from a large nationwide sample of Korean adults aged 70-84, from 10 study centers representing different regions of South Korea. We used the propensity score matching (PSM) method, which is known to minimize potential selection bias and confounding factors that are present in observational studies, and therefore, contributed to the improved internal validity of our findings [25].

\section{Materials and Methods}

\subsection{Study Population}

We used data from the Korean Frailty and Aging Cohort Study (KFACS), a populationbased prospective cohort study of older Koreans [26]. The KFACS aims to evaluate and track older adults' frailty status for 10 years and to identify relevant risk factors or outcomes. The baseline data were obtained between May 2016 and November 2017. As shown in Figure 1, ten study centers representing different regions of South Korea were chosen to increase the generalizability of the study and to address geographic variations. In each center, approximately 300 participants were recruited through quota sampling that was based on age and sex. The inclusion criteria for the study were as follows: (a) adults aged 70-84 years, (b) community-dwelling, (c) no plans to move out in two years, (d) no difficulties in communication, and (e) not diagnosed with dementia. Among a targeted total of 3000 people, half of the participants were recruited in $2016(n=1559)$ and the other half was surveyed in $2017(n=1455)$. The current study focused on those who completed the baseline interview in 2016 . We excluded 38 respondents $(2.43 \%)$ who had missing values in any variables of interest, resulting in a final analytic sample of 1521 participants.

\subsection{Measurement}

Frailty status was evaluated with the Korean frailty index (KFI), which was developed by a Korean Geriatrics Society research panel and previously validated among communitydwelling older adults $[27,28]$. The KFI consists of the following eight items: (a) a history of hospitalization in the past year $(1=$ yes $)$, (b) self-rated health status $(1=$ poor $)$, (c) weight loss in the past year to the extent that one's clothes fit loosely $(1=$ yes $),(d)$ polypharmacy ( 1 = taking four or more medications regularly), (e) depressed mood ( 1 = experiencing sadness or depressed mood for sometimes or more frequently in the last month), (f) incontinence $(1$ = experiencing incontinence of urine or feces for sometimes or more frequently in the last month), (g) visual or auditory problems ( 1 = any problems with decreased visual acuity or difficulties with hearing in daily life), and (h) physical performance measured 
with the Times Up and Go Test (TUGT) ( $1=$ taking more than 10 seconds). Respondents received 1 point if they reported a positive response for each item. Those with two or fewer points were classified as robust; those with three or four points were considered as pre-frail; those with five or more points were categorized as a frail group.

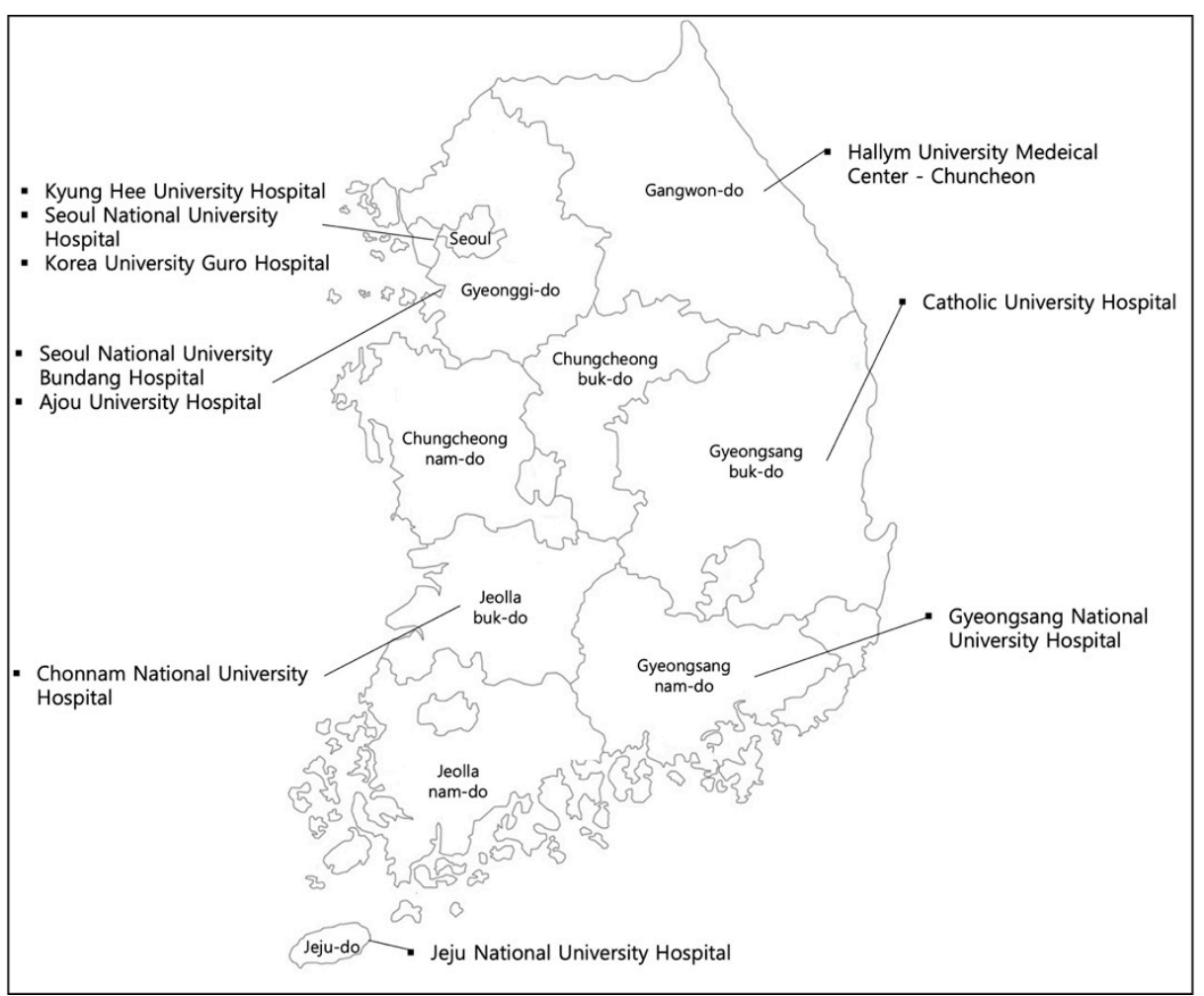

Figure 1. Ten study centers selected for the Korean Frailty and Aging Cohort Study (KFACS).

Health literacy was assessed using the three questions adopted from the Behavioral Risk Factor Surveillance System (BRFSS) questionnaire, developed by the U.S. Centers for Disease Control and Prevention. The questions were as follows: (a) "How difficult is it for you to get advice about health or medical topics if you need it?" (b) "How difficult is it for you to understand information that doctors, nurses, and other health professionals tell you?" and (c) "You can find written information about health on the internet, in newspapers and magazines, and brochures in the doctor's office and clinic; In general, how difficult is it for you to understand written health information?" The response options were "very easy," "somewhat easy," "somewhat difficult," "very difficult," and "I do not look for health information." Respondents were categorized as having limited health literacy if they answered "somewhat difficult," "very difficult," or "I do not look for health information" to one or more questions, based on previous research [29].

We included the following sociodemographic characteristics and health-related factors as control variables: gender, age, marital status (married vs. single/divorced/widowed), living arrangements (living alone, living with a spouse only, or living with a spouse and/or children), income status (receiving basic livelihood security or medical benefits vs. not eligible), educational attainment $(1=$ no formal education, $2=$ elementary school, 3 = middle school, 4 = high school, $5=$ college or above), working status (yes vs. no), current smoking (yes vs. no), alcohol drinking (yes vs. no), and fall experience in the past year (yes vs. no).

\subsection{Statistical Analysis}

The main purpose of the current study was to examine whether the limited health literacy and the nonlimited health literacy groups are at different risks of pre-frailty or 
frailty. As health literacy groups were not likely to be randomly assigned to our study population, we used the propensity score matching (PSM) method to account for potential selection and confounding biases (e.g., demographic characteristics both associated with health literacy and frailty status) [30]. The PSM method is known to reduce these biases [31], contributing to a more reasonable comparison between groups and improving the internal validity of the study findings. The strength of the PSM has broadened the range of research opportunities because it helps to analyze real-world data-nonrandomized data-with reduced selection bias [32]. However, there is criticism that PSM might be blind to the large portion of imbalance [33]. Therefore, caution is needed when conducting the PSM and interpreting the findings.

To create propensity score-matched pairs, we performed one-to-one matching using the Stata module of psmatch2 [34], where control variables of our study were used (gender, age, marital status, income status, education levels, working status, current smoking, alcohol drinking, and fall experience). The 486 nonlimited health literacy cases were matched with 486 limited health literacy cases, based on the nearest neighbor matching without replacement and conditioning on the common support. The pseudo- $\mathrm{R} 2$, an indicator of overall covariate imbalance, was lower after matching than it was before (after; pseudo$\mathrm{R} 2=0.002$, mean bias $=2.1$, median bias $=2.1, p=0.997$ vs. before; pseudo- $\mathrm{R} 2=0.143$, mean bias $=26.5$, median bias $=22.8, p<0.001$ ). These findings suggest an adequate balance of covariate distribution among the matched groups.

Figure 2 shows the standardized differences across covariates in the unmatched and matched samples. As expected, the standardized percent bias shifted toward 0 after matching. Then, we compared the limited and nonlimited health literacy groups in the full study sample (before the PSM; $n=1521)$ and the PS-matched sample $(n=972)$. Chisquare tests for categorical variables and $t$-tests for continuous variables were used to determine significant group differences. Finally, multinomial logistic regression analyses were conducted for the PSM-matched sample to examine the association between health literacy and frailty outcomes, where the robust group was set as a reference. All of the analyses were performed with Stata software version 16.0 (Stata Corporation, College Station, TX, USA).

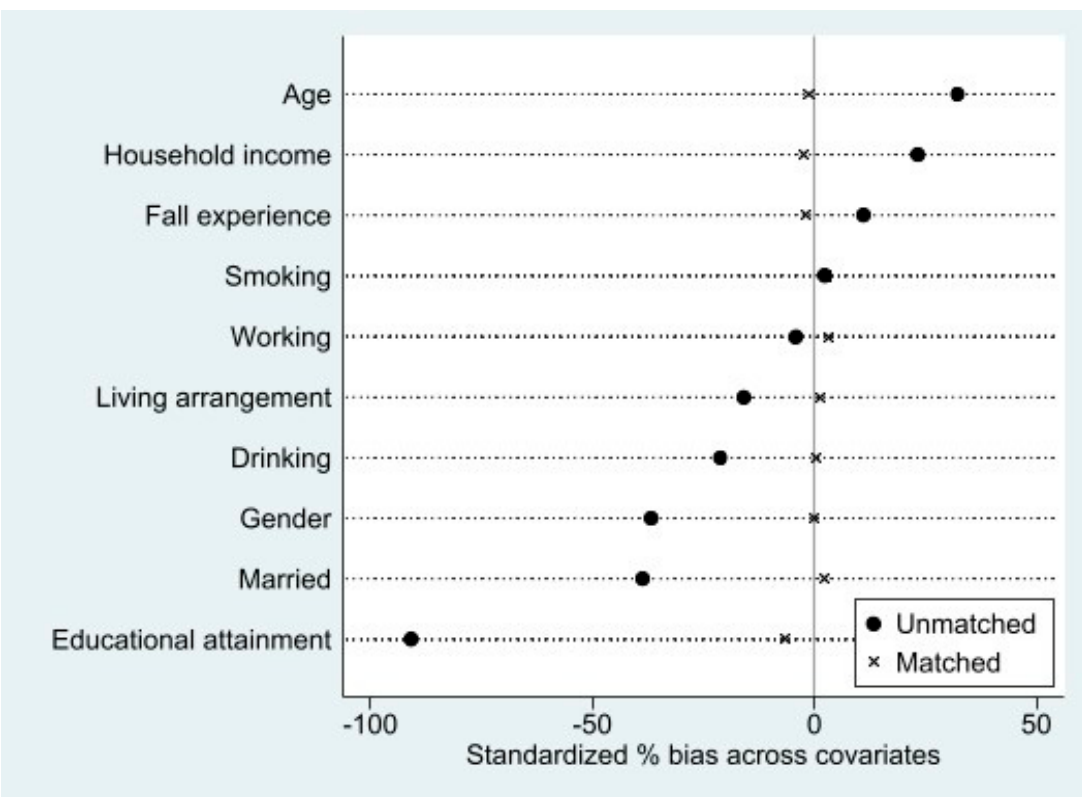

Figure 2. Visual inspection of standardized differences. 


\section{Results}

\subsection{Sample Characteristics of Limited and Nonlimited Health Literacy Groups}

Table 1 shows the descriptive characteristics between the limited health literacy (LHL) and nonlimited health literacy (Non-LHL) groups. Of the full study sample $(n=1521)$, approximately $68 \%$ had limited health literacy $(n=1035)$. Those in the LHL group were older (76.55), less likely to be married (59\%), more likely to live alone $(29 \%)$, have low household income $(9 \%)$, and reported lower educational attainment (2.35) than the NonLHL group. These demographic differences were statistically significant (Table 1). In addition, those in the LHL group were less likely to be drinking (46\%) and more likely to have fall experience (22\%) compared to the Non-LHL group. The results for both groups differed significantly (Table 1). The two groups also differed in their frailty status. Approximately $32 \%$ of the LHL group fell in the pre-frail category and $16 \%$ were in the frail category, which was significantly more than the $21 \%$ pre-frail and $5 \%$ frail in the Non-LHL group. After propensity score matching, the demographic and health-related characteristics between the LHL $(n=486)$ and Non-LHL $(n=486)$ groups were no longer significantly different. However, the LHL group still included more pre-frail $(26 \%)$ and frail $(8 \%)$ individuals than the Non-LHL group (Table 1$)$.

Table 1. Sample characteristics of the full study sample and propensity-matched sample.

\begin{tabular}{|c|c|c|c|c|c|c|c|c|c|c|}
\hline & \multicolumn{5}{|c|}{ Full Study Sample $(n=1521)$} & \multicolumn{5}{|c|}{ Matched Sample $(n=972)$} \\
\hline & \multicolumn{2}{|c|}{$\begin{array}{c}\text { LHL } \\
(n=1035)\end{array}$} & \multicolumn{2}{|c|}{$\begin{array}{l}\text { Non-LHL } \\
(n=486)\end{array}$} & \multirow[b]{2}{*}{$p$-Value } & \multicolumn{2}{|c|}{$\begin{array}{c}\text { LHL } \\
(n=486)\end{array}$} & \multicolumn{2}{|c|}{$\begin{array}{l}\text { Non-LHL } \\
(n=486)\end{array}$} & \multirow[b]{2}{*}{$p$-Value } \\
\hline & $\%$ & Mean & $\%$ & Mean & & $\%$ & Mean & $\%$ & Mean & \\
\hline \multicolumn{11}{|l|}{ Demographics } \\
\hline Male & 41.2 & & 40.9 & & & 40.9 & & 40.9 & & \\
\hline Age & & 76.55 & & 75.32 & $<0.001$ & & 75.25 & & 75.32 & 0.79 \\
\hline Married & 59.1 & & 76.5 & & $<0.001$ & 78.2 & & 76.5 & & 0.54 \\
\hline \multicolumn{11}{|l|}{ Living arrangement } \\
\hline Living alone & 29.4 & & 16.3 & & & 16.0 & & 16.3 & & 0.69 \\
\hline With a spouse only & 44.8 & & 60.1 & & 0.005 & 58.8 & & 60.1 & & \\
\hline With a spouse and/or children & 25.8 & & 23.7 & & & 25.1 & & 23.7 & & \\
\hline \multicolumn{11}{|l|}{ Household income } \\
\hline Low & 9.0 & & 3.5 & & & 2.9 & & 3.5 & & 0.58 \\
\hline Middle and upper & 91.0 & & 96.5 & & $<0.001$ & 97.1 & & 96.5 & & \\
\hline Educational attainment & & 2.35 & 0.0 & 3.50 & $<0.001$ & & 3.42 & 0.0 & 3.50 & 0.26 \\
\hline \multicolumn{11}{|l|}{ Health-related factors } \\
\hline Working & 25.2 & & 26.7 & & 0.52 & 28.0 & & 26.7 & & 0.67 \\
\hline Smoking & 5.5 & & 5.1 & & 0.77 & 6.2 & & 5.1 & & 0.49 \\
\hline Drinking & 46.2 & & 56.6 & & $<0.001$ & 57.4 & & 56.6 & & 0.80 \\
\hline Fall experience & 21.6 & & 17.3 & & 0.049 & 16.0 & & 17.3 & & 0.61 \\
\hline \multicolumn{11}{|l|}{ Frailty status } \\
\hline Robust & 52.0 & & 74.3 & & & 65.6 & & 74.3 & & \\
\hline Pre-frail & 31.9 & & 20.6 & & $<0.001$ & 25.9 & & 20.6 & & 0.002 \\
\hline Frail & 16.1 & & 5.1 & & & 8.4 & & 5.1 & & \\
\hline
\end{tabular}

Note. $\mathrm{LHL}=$ limited health literacy; to make comparisons between the health literacy groups, $t$-test was conducted for continuous variables and chi-square statistics were computed for categorical factors.

\subsection{Relative Risk Ratio of Pre-Frailty and Frailty}

Table 2 shows the relative risk ratios (RRRs) for the risk of pre-frailty and frailty in the propensity-matched sample $(n=972)$. We first conducted multinomial logistic regression analyses with a limited health literacy variable only to reduce the potential confounding effects by the treatment variables [35]. 
Table 2. Relative ratio of pre-frailty and frailty among propensity-score-matched sample $(n=972)$.

\begin{tabular}{|c|c|c|c|c|c|c|c|c|}
\hline \multirow{2}{*}{ Main variable } & \multicolumn{4}{|c|}{$\begin{array}{l}\text { Pre-Frail }(n=226) \\
\text { vs. Robust }(n=680)\end{array}$} & \multirow[b]{2}{*}{ RRR } & \multicolumn{3}{|c|}{$\begin{array}{l}\text { Frail }(n=66) \\
\text { vs. Robust }(n=680)\end{array}$} \\
\hline & \multirow{2}{*}{$\begin{array}{l}\text { RRR } \\
2.21\end{array}$} & \multicolumn{2}{|c|}{$95 \% \mathrm{CI}$} & \multirow{2}{*}{$\begin{array}{c}p \text {-Value } \\
<0.001\end{array}$} & & \multicolumn{2}{|c|}{$95 \% \mathrm{CI}$} & \multirow{2}{*}{$\begin{array}{l}p \text {-Value } \\
<0.001\end{array}$} \\
\hline Limited health literacy & & 1.70 & 2.87 & & 4.48 & 2.88 & 6.96 & \\
\hline Main variable & & & & & & & & \\
\hline $\begin{array}{l}\text { Limited health literacy } \\
\text { Demographics }\end{array}$ & 1.45 & 1.06 & 1.98 & 0.02 & 2.03 & 1.19 & 3.49 & 0.01 \\
\hline Male & 0.76 & 0.52 & 1.12 & 0.17 & 2.62 & 1.30 & 5.26 & 0.01 \\
\hline Age & 1.07 & 1.03 & 1.12 & $<0.001$ & 1.10 & 1.02 & 1.18 & 0.01 \\
\hline $\begin{array}{l}\text { Married } \\
\text { Living arrangement }(\operatorname{Ref}=\text { alone }\end{array}$ & 1.19 & 0.60 & 2.34 & 0.62 & 2.95 & 0.66 & 13.13 & 0.16 \\
\hline With a spouse only & 0.90 & 0.42 & 1.93 & 0.78 & 0.15 & 0.03 & 0.64 & 0.01 \\
\hline With a spouse and/or children & 0.72 & 0.37 & 1.38 & 0.32 & 0.10 & 0.02 & 0.43 & $<0.001$ \\
\hline Low income & 1.31 & 0.53 & 3.24 & 0.56 & 1.73 & 0.54 & 5.53 & 0.35 \\
\hline Educational attainment & 0.81 & 0.71 & 0.94 & 0.01 & 0.68 & 0.53 & 0.88 & $<0.001$ \\
\hline $\begin{array}{l}\text { Health-related factors } \\
\text { Working }\end{array}$ & & & & & & & & \\
\hline Working & 0.85 & 0.59 & 1.22 & 0.38 & 0.49 & 0.25 & 0.97 & 0.04 \\
\hline Smoking & 1.22 & 0.61 & 2.44 & 0.57 & 1.21 & 0.46 & 3.18 & 0.70 \\
\hline Drinking & 0.92 & 0.67 & 1.28 & 0.64 & 0.60 & 0.35 & 1.03 & 0.07 \\
\hline Fall experience & 2.01 & 1.37 & 2.95 & $<0.001$ & 1.71 & 0.89 & 3.29 & 0.11 \\
\hline
\end{tabular}

Note. $R R R=$ relative risk ratio.

After adjusting for demographic and health-related factors, limited health literacy significantly increased the risk of pre-frailty $(R R R=1.45,95 \% \mathrm{CI}=1.06-1.98, p=0.02)$ and frailty $(\mathrm{RRR}=2.03,95 \% \mathrm{CI}=1.19-3.49, p=0.01)$. Concerning the covariates, the risk of pre-frailty was significantly associated with age $(\mathrm{RRR}=1.07,95 \% \mathrm{CI}=1.03-1.12, p<0.001)$, educational attainment $(\mathrm{RRR}=0.81,95 \% \mathrm{CI}=0.71-0.94, p=0.01)$, and fall experience (RRR $=2.01,95 \% \mathrm{CI}=1.37-2.95, p<0.001)$. The risk of frailty was significantly increased by being male $(\mathrm{RRR}=2.62,95 \% \mathrm{CI}=1.30-5.26, p=0.01)$ and being of an older age $(\mathrm{RRR}=1.10$, $95 \% \mathrm{CI}=1.02-1.18, p=0.01)$, but decreased by living with a spouse $(\mathrm{RRR}=0.15,95 \% \mathrm{CI}=$ $0.03-0.64, p=0.01)$, living with a spouse and / or children ( $R R R=0.10,95 \% \mathrm{CI}=0.02-0.43, p$ $<0.001)$, having higher educational attainment $(\mathrm{RRR}=0.68,95 \% \mathrm{CI}=0.53-0.88, p<0.001)$, and working $(\mathrm{RRR}=0.49,95 \% \mathrm{CI}=0.25-0.97, p=0.04)$.

\subsection{Sensitivity Analyses}

We also examined the association between frailty status and health literacy among the full study sample. As presented in Table 3, the findings remained similar to the propensity-matched sample. Limited health literacy was related to an increased risk of both pre-frailty $(\mathrm{RRR}=1.50,95 \% \mathrm{CI}=1.13-2.00, p=0.01)$ and frailty $(\mathrm{RRR}=2.31,95 \% \mathrm{CI}$ $=1.43-3.73, p<0.001)$. A few differences were found in the associations between gender, living arrangements, and fall experience in relation to frailty status. In the full sample, being male was not significantly associated with an increased risk of frailty ( $R R R=1.06$, $95 \% \mathrm{CI}=0.69-1.62, p=0.81$ ), whereas living with a spouse compared to living alone did not itself decrease the risk of frailty ( $R R R=0.72,95 \% \mathrm{CI}=0.34-1.55, p=0.40)$. Fall experience, however, was significantly related to an increased risk of frailty $(\mathrm{RRR}=2.17,95 \% \mathrm{CI}=$ $1.49-3.17, p<0.001)$. 
Table 3. Relative risk ratio of pre-frailty and frailty among the full study sample $(n=1521)$.

\begin{tabular}{|c|c|c|c|c|c|c|c|c|}
\hline \multirow{2}{*}{ Main variable } & \multicolumn{4}{|c|}{$\begin{array}{l}\text { Pre-Frail }(n=430) \\
\text { vs. Robust }(n=899)\end{array}$} & \multirow[b]{2}{*}{ RRR } & \multicolumn{3}{|c|}{$\begin{array}{l}\text { Frail }(n=192) \\
\text { vs. Robust }(n=899)\end{array}$} \\
\hline & \multirow{2}{*}{$\begin{array}{l}\text { RRR } \\
2.22\end{array}$} & \multicolumn{2}{|c|}{$95 \%$ CI } & \multirow{2}{*}{$\begin{array}{c}p \text {-Value } \\
<0.001\end{array}$} & & \multicolumn{2}{|c|}{$95 \%$ CI } & \multirow{2}{*}{$\begin{array}{l}p \text {-Value } \\
<0.001\end{array}$} \\
\hline Limited health literacy & & 1.71 & 2.87 & & 4.66 & 3.00 & 7.24 & \\
\hline Main variable & & & & & & & & \\
\hline $\begin{array}{l}\text { Limited health literacy } \\
\text { Demographics }\end{array}$ & 1.50 & 1.13 & 2.00 & 0.01 & 2.31 & 1.43 & 3.73 & $<0.001$ \\
\hline Male & 0.76 & 0.56 & 1.02 & 0.07 & 1.06 & 0.69 & 1.62 & 0.81 \\
\hline Age & 1.08 & 1.05 & 1.12 & $<0.001$ & 1.14 & 1.09 & 1.19 & $<0.001$ \\
\hline $\begin{array}{l}\text { Married } \\
\text { Living arrangement }(\text { Ref }=\text { alone })\end{array}$ & 0.94 & 0.57 & 1.55 & 0.82 & 1.20 & 0.59 & 2.41 & 0.61 \\
\hline With a spouse only & 1.01 & 0.59 & 1.75 & 0.96 & 0.72 & 0.34 & 1.55 & 0.40 \\
\hline With a spouse and/or children & 0.68 & 0.45 & 1.04 & 0.07 & 0.55 & 0.31 & 0.98 & 0.04 \\
\hline Low income & 1.20 & 0.75 & 1.93 & 0.45 & 1.15 & 0.64 & 2.09 & 0.64 \\
\hline Educational attainment & 0.78 & 0.71 & 0.87 & $<0.001$ & 0.64 & 0.55 & 0.75 & $<0.001$ \\
\hline Health-related factors & & & & & & & & \\
\hline Working & 0.83 & 0.63 & 1.11 & 0.21 & 0.50 & 0.32 & 0.77 & $<0.001$ \\
\hline Smoking & 0.97 & 0.54 & 1.74 & 0.93 & 1.78 & 0.92 & 3.44 & 0.09 \\
\hline Drinking & 0.95 & 0.74 & 1.22 & 0.67 & 0.74 & 0.52 & 1.05 & 0.09 \\
\hline Fall experience & 1.48 & 1.10 & 2.00 & 0.01 & 2.17 & 1.49 & 3.17 & $<0.001$ \\
\hline
\end{tabular}

Note. $R R R=$ relative risk ratio.

\section{Discussion}

As of 2017, South Korea became an older society in which adults aged 65 and above accounted for over $14 \%$ of the total population. By 2025, the nation is expected to become a super-aged society, as the ratio increases to $20.3 \%$ [36]. Older Koreans have approximately 2.7 chronic diseases on average [37]. Approximately $47 \%$ and $8 \%$ are estimated to have prefrailty and frailty, respectively $[26,28]$. In light of this social context, there is an increasing need to identify preventive and risk factors of pre-frailty and frailty $[7,8]$. The current study focused on the role of health literacy in determining frailty status among communitydwelling older adults in South Korea.

Our analyses with a nationwide sample found that approximately $32 \%$ and $16 \%$ of participants with limited health literacy (LHL) fell into the categories of pre-frail and frail, respectively. These rates were significantly higher compared to the $21 \%$ of pre-frailty and $5 \%$ of frailty in the nonlimited health literacy (Non-LHL) group. The findings from the multiple logistic regression showed that LHL significantly increased the risk of pre-frailty and frailty, even after a propensity score matching for demographic and other health factors. These findings are consistent with previous evidence [18,21-23], suggesting that a health literacy education and intervention program can be an effective strategy to prevent and decrease the risk of frailty. Indeed, systematic research has suggested that improving health literacy can facilitate subsequent health behavior changes, such as better diet quality, increased physical activity, and smoking cessation $[16,38]$. A recent intervention study targeting older adults with low health literacy [39] found that an active learning program is effective in promoting a healthier lifestyle (i.e., moderate-to-vigorous physical activity and dietary variety), which is itself a known protective factor against the development of frailty [40].

Furthermore, we identified different sets of demographic and health-related predictors of pre-frailty and frailty. In line with prior studies [41,42], age and educational attainment were significantly associated with the risk of pre-frailty and frailty. Fall experience had a significant relationship with pre-frailty status only, whereas being male, living alone, and nonworking status were related to an increased risk of frailty. It was notable that factors related to social activities (i.e., living arrangements and working status) were associated with frailty status (vs. robust). These findings generally follow the literature 
reporting several risk factors of pre-frailty and frailty [43-45]. Therefore, when planning intervention programs, more attention should be paid to vulnerable groups with limited sociodemographic data. For example, interventions for older adults living alone should involve a connection to local community centers, where a variety type of preventative programs for frailty can be provided.

Some major strengths of our study include the use of a nationwide sample of older Koreans collected from 10 representative cities/provinces of South Korea; this approach addresses the paucity of research on this topic with a large sample of older adults. Additionally, we accounted for potential selection effects and confounding biases between health literacy groups through the PSM method. To the best of our knowledge, this study is the first to examine the role of limited health literacy in frailty outcomes using the PSM method.

It is important to note some limitations of our study when interpreting the findings. The cross-sectional design did not allow us to establish a direct causal relationship between independent variables and frailty. Second, we did not measure participants' previous experiences with health-related education or programs, which may have influenced the association between health literacy level and frailty status. Lastly, future studies need to address the overmatching problem more carefully by conducting the robustness checks. Future studies would benefit from employing a more comprehensive range of control variables to further clarify the positive effects of health literacy in preventing frailty.

\section{Conclusions}

The current study showed that limited health literacy is associated with an increased risk of pre-frailty and frailty among community-dwelling older adults. Our findings not only underscore the need to foster health literacy intervention programs, but also to provide preliminary evidence to inform tailored intervention programs by demographic and health-related factors to attenuate the risk of frailty in the older population.

Author Contributions: Conceptualization, H.-R.S. and Y.-S.K.; methodology, H.-R.S. and E.-Y.C.; formal analysis, H.-R.S.; investigation, H.-R.S. and S.-K.K.; resources, Y.-S.K.; data curation, S.-K.K.; writing-original draft preparation, H.-R.S., E.-Y.C. and S.-K.K.; writing-review and editing, H.-Y.L. and Y.-S.K.; supervision, Y.-S.K.; funding acquisition, Y.-S.K. All authors have read and agreed to the published version of the manuscript.

Funding: This research was supported by a grant from the Korea Health Technology R\&D Project through the Korea Health Industry Development Institute, which is funded by the Ministry of Health and Welfare, Republic of Korea (Project No. HI15C3153) and a grant from Kyung Hee University in 2017 (Project No. KHU-20170721).

Institutional Review Board Statement: The KFACS protocol was approved by the institutional review boards (IRBs) of the clinical research ethics committees of all 10 participating centers (Kyung Hee University, Seoul National University Hospital, Korea University Guro Hospital, Hallym University Medical Center-Chuncheon, Seoul National University Bundang Hospital, Ajou University Hospital, Gyeongsang National University Hospital, Chonnam National University Hospital, and Jeju National University Hospital), including the coordinating center, Kyung Hee University Hospital, Seoul, Korea (IRB number: 2015-12-103).

Informed Consent Statement: Informed consent was obtained from all subjects involved in the study.

Acknowledgments: The authors would like to thank the study participants and the Korean Frailty and Aging Cohort Study staff for their cooperation in this study.

Conflicts of Interest: The authors declare no conflict of interest.

\section{References}

1. Fried, L.P.; Ferrucci, L.; Darer, J.; Williamson, J.D.; Anderson, G. Untangling the concepts of disability, frailty, and comorbidity: Implications for improved targeting and care. J. Gerontol. A Biol. Sci. Med. Sci 2004, 59, M255-M263. [CrossRef] [PubMed] 
2. $\quad$ Ensrud, K.E.; Ewing, S.K.; Cawthon, P.M.; Fink, H.A.; Taylor, B.C.; Cauley, J.A.; Dam, T.T.; Marshall, L.M.; Orwoll, E.S.; Cummings, S.R.; et al. A comparison of frailty indexes for the prediction of falls, disability, fractures, and mortality in older men. J. Am. Geriatr. Soc. 2009, 57, 492-498. [CrossRef]

3. Vermeiren, S.; Vella-Azzopardi, R.; Beckwee, D.; Habbig, A.K.; Scafoglieri, A.; Jansen, B.; Bautmans, I. Gerontopole Brussels Study Group. Frailty and the prediction of negative health outcomes: A meta-analysis. J. Am. Med. Dir. Assoc. 2016, 17, 1163.e1-1163.e17. [CrossRef] [PubMed]

4. $\quad$ Fried, L.P.; Tangen, C.M.; Walston, J.; Newman, A.B.; Hirsch, C.; Gottdiener, J.; Seeman, T.; Tracy, R.; Kop, W.J.; Burke, G.; et al. Frailty in older adults: Evidence for a phenotype. J. Gerontol. Ser. A Biol. Sci. Med. Sci. 2001, 56, M146-M157. [CrossRef]

5. Grden, C.R.B.; Lenardt, M.H.; Sousa, J.A.V.D.; Kusomota, L.; Dellaroza, M.S.G.; Betiolli, S.E. Associations between frailty syndrome and sociodemographic characteristics in long-lived individuals of a community. Rev. Lat. Am. Enferm. 2017, 25, e2886. [CrossRef]

6. Hanlon, P.; Nicholl, B.I.; Jani, B.D.; Lee, D.; McQueenie, R.; Mair, F.S. Frailty and pre-frailty in middle-aged and older adults and its association with multimorbidity and mortality: A prospective analysis of 493737 UK Biobank participants. Lancet Public Health 2018, 3, e323-e332. [CrossRef]

7. Hajek, A.; Bock, J.O.; Saum, K.U.; Matschinger, H.; Brenner, H.; Holleczek, B.; Haefeli, W.E.; Heider, D.; König, H.H. Frailty and healthcare costs-Longitudinal results of a prospective cohort study. Age Ageing 2018, 47, 233-241. [CrossRef]

8. Gale, C.R.; Westbury, L.; Cooper, C. Social isolation and loneliness as risk factors for the progression of frailty: The English Longitudinal Study of Ageing. Age Ageing 2018, 47, 392-397. [CrossRef]

9. Khezrian, M.; Myint, P.K.; McNeil, C.; Murray, A.D. A review of frailty syndrome and its physical, cognitive and emotional domains in the elderly. Geriatrics 2017, 2, 36. [CrossRef]

10. Yamada, Y.; Eto, M.; Kojima, T.; Umeda-Kameyama, Y.; Ogawa, S.; Akishita, M. Predictive factors for the practical management of the anticoagulant therapy in frail old patients. Innov. Aging 2017, 1 (Suppl. S1), 1155. [CrossRef]

11. Ma, L.; Zhang, L.; Sun, F.; Li, Y.; Tang, Z. Cognitive function in Prefrail and frail community-dwelling older adults in China. BMC Geriatr. 2019, 19, 1-7. [CrossRef] [PubMed]

12. Kickbusch, I.; Pelikan, J.M.; Apfel, F.; Tsouros, A.D. Health Literacy: The Solid Facts; WHO Regional Office for Europe: Copenhagen, Denmark, 2013; pp. 1-86. ISBN 978-928-900-015-4.

13. Howard, D.H.; Gazmararian, J.; Parker, R.M. The impact of low health literacy on the medical costs of Medicare managed care enrollees. Am. J. Med. 2005, 118, 371-377. [CrossRef] [PubMed]

14. Friedman, D.B.; Hoffman-Goetz, L.; Arocha, J.F. Health literacy and the World Wide Web: Comparing the readability of leading incident cancers on the Internet. Med. Inform. Internet Med. 2006, 31, 67-87. [CrossRef]

15. Bittermann, T.; Dwinnells, K.; Chadha, S.; Wolf, M.S.; Olthoff, K.M.; Serper, M. Low health literacy is associated with frailty and reduced likelihood of liver transplant listing: A prospective cohort study. Liver Transplant. 2020, 26, 1409-1421. [CrossRef]

16. Berkman, N.D.; Sheridan, S.L.; Donahue, K.E.; Halpern, D.J.; Crotty, K. Low health literacy and health outcomes: An updated systematic review. Ann. Intern. Med. 2011, 155, 97-107. [CrossRef]

17. Cajita, M.I.; Cajita, T.R.; Han, H.R. Health literacy and heart failure: A systematic review. J. Cardiovasc. Nurs. 2016, 31, 121. [CrossRef] [PubMed]

18. Huang, C.H.; Lai, Y.C.; Lee, Y.C.; Teong, X.T.; Kuzuya, M.; Kuo, K.M. Impact of health literacy on frailty among communitydwelling seniors. Clin. Med. 2018, 7, 481. [CrossRef]

19. Liu, Y.; Meng, H.; Tu, N.; Liu, D. The Relationship Between Health Literacy, Social support, depression, and frailty among community-dwelling older patients with hypertension and diabetes in China. Front. Public Health 2020, 8, 280. [CrossRef] [PubMed]

20. Sagong, H.; Yoon, J.Y. Pathways among frailty, health Literacy, acculturation, and social support of middle-aged and older Korean immigrants in the USA. Int. J. Environ. Res. Public Health 2021, 18, 1245. [CrossRef] [PubMed]

21. Shah, A.; Ferri-Guerra, J.; Nadeem, M.Y.; Salguero, D.; Aparicio-Ugarriza, R.; Desir, M.; Ruiz, J.G. The association of health literacy, numeracy and graph literacy with frailty. Aging Clin. Exp. Res. 2019, 31, 1827-1832. [CrossRef]

22. Shirooka, H.; Nishiguchi, S.; Fukutani, N.; Adachi, D.; Tashiro, Y.; Hotta, T.; Morini, S.; Nozaki, Y.; Hirata, H.; Yamaguchi, M.; et al. Association between comprehensive health literacy and frailty level in community-dwelling older adults: A cross-sectional study in Japan. Geriatr. Gerontol. Int. 2017, 17, 804-809. [CrossRef] [PubMed]

23. Yamada, M.; Kimura, Y.; Ishiyama, D.; Otobe, Y.; Suzuki, M.; Koyama, S.; Kikychi, T.; Kusumi, H.; Arai, H. Effect of the COVID-19 epidemic on physical activity in community-dwelling older adults in Japan: A cross-sectional online survey. J. Nutr. Health. Aging 2020, 24, 948-950. [CrossRef] [PubMed]

24. Ysea-Hill, O.; Sani, T.N.; Nasr, L.A.; Gomez, C.J.; Ganta, N.; Sikandar, S.; Theou, O.; Ruiz, J.G. Concurrent Validity of Pictorial Fit-Frail Scale (PFFS) in Older Adult Male Veterans with Different Levels of Health Literacy. Gerontol. Geriatr. Med. 2021, 7, 1-7. [CrossRef]

25. Joffe, M.M.; Rosenbaum, P.R. Invited commentary: Propensity scores. Am. J. Epidemiol. 1999, 150, 327-333. [CrossRef]

26. Won, C.W.; Lee, S.Y.; Kim, J.H.; Chon, D.K.; Kim, S.Y.; Kim, C.O.; Kim, M.K.; Cho, B.; Choi, K.M.; Roh, E.; et al. Korean frailty and aging cohort study (KFACS): Cohort profile. BMJ Open 2020, 10, e035573. [CrossRef]

27. Hwang, H.S.; Kwon, I.S.; Park, B.J.; Cho, B.; Yoon, J.L.; Won, C.W. The validity and reliability of Korean frailty index. Hanguk. Nonyonhak 2010, 14, 191-202. [CrossRef] 
28. Jung, H.W.; Kim, S.; Won, C.W. Validation of the Korean Frailty Index in community-dwelling older adults in a nationwide Korean Frailty and Aging Cohort study. Korean J. Intern. Med. 2021, 36, 456-466. [CrossRef]

29. Roy, M.; Hege, A.; Bouldin, E. Impact of Low Health Literacy on Adverse Health Behaviors in the State of North Carolina, 2016. Available online: https:/ / prod.wp.cdn.aws.wfu.edu/sites/273/2019/11/Manan-Roy.pdf (accessed on 26 July 2021).

30. Fujii, T.; Kitamura, T.; Kajino, K.; Kiyohara, K.; Nishiyama, C.; Nishiuchi, T.; Hayashi, Y.; Kawamura, T.; Iwami, T. Prehospital intravenous access for survival from out-of-hospital cardiac arrest: Propensity score matched analyses from a population-based cohort study in Osaka, Japan. BMJ Open 2017, 7, e015055. [CrossRef] [PubMed]

31. Fang, Z.; Li, P.; Liu, J.; Chong, W.; Du, F.; Wu, H.; Liu, Y.; Lu, J.; Li, F.; Shanf, L.; et al. Impact of Low Skeletal Muscle Mass on Complications and Survival for Gastric Cancer: A Propensity Score Matching Analysis. World J. Surg. Oncol 2021, $22,1-15$. [CrossRef]

32. Staffa, S.J.; Zurakowski, D. Five steps to successfully implement and evaluate propensity score matching in clinical research studies. Anesth. Analg. 2018, 127, 1066-1073. [CrossRef]

33. King, G.; Nielsen, R. Why propensity scores should not be used for matching. Political Anal. 2019, 27, 435-454. [CrossRef]

34. Leuven, E.; Sianesi, B. PSMATCH2: Stata Module to Perform Full Mahalanobis and Propensity Score Matching, Common Support Graphing, and Covariate Imbalance Testing; Boston College Department of Economics: Chestnut Hill, MA, USA, 2018.

35. Baser, O. Too much ado about propensity score models? Comparing methods of propensity score matching. Value Health 2006, 9 , 377-385. [CrossRef] [PubMed]

36. Kang, Y.K.; Lee, P.Y.; Bae, Y.S. Senior Statistics; Statistics Korea: Daejeon, Korea, 2020.

37. Jung, K.H.; Oh, Y.H.; Kang, E.N.; Kim, K.R.; Lee, Y.K.; Oh, M.A.; Hwang, N.H.; Kim, S.J.; Lee, S.H.; Lee, S.K.; et al. 2017 National Survey of Elderly; Korea Institute for Health and Social Affairs: Sejong, Korea, 2017; Volume 53, pp. 1-911.

38. Walters, R.; Leslie, S.J.; Polson, R.; Cusack, T.; Gorely, T. Establishing the efficacy of interventions to improve health literacy and health behaviours: A systematic review. BMC Public Health 2020, 20, 1-17. [CrossRef] [PubMed]

39. Uemura, K.; Yamada, M.; Okamoto, H. The effectiveness of an active learning program in promoting a healthy lifestyle among older adults with low health literacy: A randomized controlled trial. Gerontology 2021, 67, 25-35. [CrossRef] [PubMed]

40. Feng, Z.; Lugtenberg, M.; Franse, C.; Fang, X.; Hu, S.; Jin, C.; Raat, H. Risk factors and protective factors associated with incident or increase of frailty among community-dwelling older adults: A systematic review of longitudinal studies. PLoS ONE 2017, 12, e0178383. [CrossRef]

41. Wong, C.H.; Weiss, D.; Sourial, N.; Karunananthan, S.; Quail, J.M.; Wolfson, C.; Bergman, H. Frailty and its association with disability and comorbidity in a community-dwelling sample of seniors in Montreal: A cross-sectional study. Aging Clin. Exp. Res. 2010, 22, 54-62. [CrossRef]

42. Buttery, A.K.; Busch, M.A.; Gaertner, B.; Scheidt-Nave, C.; Fuchs, J. Prevalence and correlates of frailty among older adults: Findings from the German health interview and examination survey. BMC Geriatr. 2015, 15, 1-9. [CrossRef] [PubMed]

43. Cho, S.E.; Choi, E.Y.; Oh, Y.S.; Kim, Y.S.; Kim, S.B. Investigating the predictors of frailty: An age-dependent analysis. Health Soc. Welf. Rev. 2017, 37, 139-169. [CrossRef]

44. Clegg, A.; Young, J.; Lliffe, S.; Rikkert, M.O.; Rockwood, K. Frailtyin elderly people. Lancet 2013, 381, 752-762. [CrossRef]

45. Ensrud, K.E.; Ewing, S.K.; Taylor, B.C.; Fink, H.A.; Stone, K.L.; Cauley, J.A.; Tracy, J.A.; Hochberg, M.C.; Rodond, N.; Cawthon, P.M. Frailty and risk of falls, fracture, and mortality in older women:the study of osteoporotic fractures. J. Gerontol. A Biol. Sci. Med. Sci. 2007, 62, 744-751. [CrossRef] [PubMed] 